\title{
Estudos de cultura material: uma vertente francesa
}

\author{
Marcelo Rede \\ Universidade Federal Fluminense
}

Até a década de noventa, os estudos de cultura material tiveram, na França, uma trajetória inconstante e aleatória. Alguns esforços são dignos de nota, mas não contribuíram de modo decisivo para a constituição de um campo de pesquisa. Faltaram, ou foram débeis, os requisitos elementares para tanto - a busca de instrumentos metodológicos, o debate a fim de definir ou afinar os conceitos teóricos, o exercício aplicado a casos particulares - tudo o que, enfim, permite definir um domínio de saber. Por outro lado, as tentativas restaram isoladas em campos que nem sempre se comunicaram abertamente - do pensamento filosófico à sociologia, passando pela historiografia -, o que contribuiu para a pulverização da reflexão.

É sintomático deste quadro o fato de o livro de Baudrillard, Le système des objets (1968), ter-se tornado uma referência constante e, ao mesmo tempo, ter permanecido como o produto de uma tendência particular, aquela da semiologia, pronta a oferecer uma chave de leitura aos diversos fenômenos da vida social da palavra à imagem, passando pelos objetos -, sempre a partir de métodos e conceitos cujas origens se localizavam na lingüística. Apesar de algumas diferenças importantes, o Théorie des objets de Moles (1972) compartilhava com a obra de Baudrillard duas características essenciais: a preocupação em descrever o papel das coisas materiais na sociedade moderna e, sobretudo, a valorização da função sígnica dos objetos.

Por outro lado, no domínio historiográfico, alguns esforços prolongaram a sugestão de Braudel de inserir no horizonte de uma história econômico-social a dimensão palpável da "civilização material". No entanto, mesmo no interior de uma tendência caracteristicamente dinâmica como a Escola dos Annales, seria preciso chamar a atenção para certos limites. Leia-se o capítulo de Pesez (1978) sobre a 
cultura material no volume programático editado por Jacques Le Goff, Roger Chartier e Jacques Revel, e se perceberá quer a ausência de conceitos satisfatórios dos elementos implicados, quer a debilidade das propostas analíticas apresentadas, em geral derivadas de uma transferência um tanto irrefletida dos procedimentos da arqueologia para o campo da história. Os estudos monográficos, por seu lado, parecem ter assimilado o apelo a uma atenção à cultura material, sobretudo como uma sugestão de renovação das temáticas da "nova história". Assim, a obra bastante característica de Roche (1997) sobre o nascimento das formas modernas de consumo a partir do século XVII mobiliza intensamente o universo da cultura material la casa, as estruturas de iluminação, aquecimento e abastecimento de água, os móveis e objetos, as vestes, os alimentos) com o intuito de estabelecer as novas articulações da vida cotidiana, as alterações nos padrões de sociabilidade, em face das transformações no sistema de produção, circulação e consumo. No entanto, a exploração dessa fronteira não parece ter exigido, e isto é o mais surpreendente, nenhuma renovação no arsenal analítico tradicional do historiador: através das páginas do livro, são os documentos escritos que são mobilizados para dar conta da relação entre sociedade e matéria. A operação historiográfica não se alterou substancialmente com a renovação do temário; dito de outro modo, o reconhecimento da cultura material como parte essencial do fenômeno histórico não implicou sua inserção decisiva como documento no processo de produção do discurso historiográfico. Mesmo se, com os Annales, os estudos de cultura material distanciaramse da abordagem tradicional da história das técnicas, restringiram-se finalmente ao papel de complemento à história das mentalidades.

Na última década, contudo, um elemento novo foi introduzido no quadro. Partindo desta vez da antropologia, um movimento propõe relançar os estudos de cultura material. Seu caráter, à diferença dos anteriores, é orgânico, ao menos o suficiente para que se possa falar de um grupo de estudiosos que partilham certa gama de interesses e preocupações. Uma organicidade que se traduz em institucionalização: congregação dos pesquisadores em torno de uma Universidade (Paris $V$ - René Descartes), constituição de um grupo de trabalho (Matière à Penser, fundado em 1995), organização de seminários e colóquios, divulgação editorial dos trabalhos (não sendo desinteressante notar a concentração das publicações em um editor do Quartier Latin, L'Harmattan; o volume sob resenha, publicado pela PUF, fazendo as vezes de exceção, mas também sinalizando uma penetração mais larga do grupo). Um movimento, por fim, francês: no sentido de que procura se enraizar em uma tradição antropológica local laquela de Mauss, a que se esforça, não obstante, por superar, como veremos), marcando as diferenças com os estudos de cultura material do mundo anglo-americano lem particular, a tradição dos "american studies") mesmo se se mantém aberta ao diálogo.

Alguns nomes são recorrentes, como Céline Rosselin, Marie-Pierre Julien, Isabelle Garabau-Moussaoiu e, sobretudo, Pierre Parlebas e Jean-Pierre Warnier. Parlebas, sociólogo dos jogos e dos esportes, é o principal teórico de um domínio caro ao grupo: a motricidade, a problemática do comportamento corporal e de sua articulação com o universo físico. É, no entanto, a Jean-Pierre Warnier que cabe o papel de principal sintetizador dos argumentos teóricos e metodológicos da corrente. Ao analisar sua mais recente obra - Construire la culture matérielle -, o que se propõe aqui é explicitar seus postulados e seus procedimentos analíticos, bem como, em um segundo momento, avaliar criticamente as suas potencialidades e suas limitações, sempre sob a óptica das particularidades da pesquisa em história. 
Motricidade: corpo e cultura material

Uma parte considerável da cultura material é formada por objetos manipuláveis. Sua função social se estabelece, então, em uma relação imediata e direta com o corpo. Mesmo para os demais, cuja manipulação é casual ou indireta, a relação com o corpo continua a ser fundamental, pois não se trata apenas de um contato físico imediato, mas também de articulações menos evidentes e que, no cotidiano, podem passar despercebidas, como, por exemplo, a disposição espacial dos elementos no ambiente freqüentado pelo corpo. Certas situações diluem consideravelmente a percepção do vínculo físico, é o caso da articulação corpo-paisagem ou das relações em que os contatos são predominantemente visuais. No entanto, em todos os casos, o corpo se impõe como um balizador maior da experiência material do homem (do indivíduo, como da sociedade) e, por conseqüência, como variante importante do estudo antropológico. De onde a ênfase de Parlebas e Warnier e seus seguidores na articulação entre o corpo e a cultura material e do resgate de um texto largamente subestimado de Mauss.

De fato, em 1936, Mauss assinava no Journal de Psychologie um artigo intitulado "As técnicas do corpo", em que procurava estabelecer as bases para um estudo antropológico do comportamento corporal. A intenção era demonstrar o caráter cultural das condutas corporais, explicando as diferenças observadas etnograficamente las várias formas de nadar ou de manter-se agachado, por exemplo). Dois aspectos desse texto nos interessam mais de perto, pois encontram-se no centro de sua apropriação por Warnier.

De início, a própria delimitação do objeto de estudo. Mauss, distanciando-se do método arqueológico ou dos estudos de materiais etnográficos, focalizou sua atenção sobre o corpo em detrimento dos objetos ou instrumentos. Trata-se de uma ênfase consciente e que acarreta algumas conseqüências importantes. Objetivo de Mauss era lançar luz sobre um domínio até então oculto pela noção tradicional de tecnologia: em geral, diz ele, considera-se equivocadamente que existe tecnologia quando um instrumento é envolvido no ato de manipulação. A esta "technique à instrument", Mauss opõe um conjunto de "techniques du corps", às quais confere mesmo um papel preliminar: o corpo é o primeiro instrumento a dominar, aquele que intermedeia a relação com todos os demais.

Se Mauss estimulava, assim, a consideração do corpo no estudo das práticas sociais, ao mesmo tempo, na avaliação de Warnier, marginalizava a cultura material de um modo que, ao final das contas, é inócuo, pois, como mostra o próprio texto de Mauss, os elementos físicos exteriores ao corpo são onipresentes e sua consideração se impõe ao estudioso. Cumpre, então, superar a dicotomia estabelecida por Mauss (mais pedagógica do que ontológica, em todo caso), e propor uma análise das práticas sociais através da articulação entre corpo e cultura material, entre as condutas motoras e os elementos que compõem o quadro físico da vida. $\bigcirc$ "corpo a corpo com o objeto", para retomar uma expressão cara ao grupo, transforma-se, então, em campo de observação e potencial revelador das relações sociais. A partir da herança de Mauss, portanto, o grupo posiciona no centro de suas reflexões o problema da motricidade, mas enfatiza que ela não se realiza num vácuo físico: ao contrário, não apenas a conduta corporal se estabelece em função de parâmetros materiais /que the oferecem 
as possibilidades e os limites), mas também, aprofundando ainda mais o postulado, pode-se dizer que o universo material é parte constitutiva da própria corporalidade, que o corpo se constrói pela materialidade que lhe é exterior a princípio. Mais do que uma prótese do corpo - que lhe supriria, então, uma lacuna - , a cultura material participa de uma síntese que, longe de ser estática, implica interação dinâmica entre os elementos em jogo: corpo, objeto, espaço. Assim, o foco da análise será concentrado sobre o processo de incorporação, isto é, a apropriação do universo físico mediada pelo corpo.

texto de Mauss fornecia, ainda, um segundo aspecto importante, que Warnier busca igualmente aproveitar e remodelar: trata-se da forma de articulação entre o nível individual e biológico, de um lado, e o nível coletivo e social, de outro. Não será necessário insistir, aqui, sobre a importância da questão para Mauss, uma vez que ela se posiciona em pleno coração de sua idéia de homem total. Apenas lembremos que sua resposta fora francamente influenciada pelos trabalhos dos psicólogos, de quem ele se aproximava nas primeiras décadas do século. Se a sociedade estabelece esquemas de referência para que o indivíduo se posicione diante do coletivo, ao mesmo tempo a psicologia individual fornece os mecanismos de interação entre o sujeito corporal e a sociedade. As "roves d'engrenages" de Mauss situam-se em uma esfera subjetiva.

Na seqüência dessa idéia, Warnier enfatizará o sujeito como sede da operação que articula os diversos níveis da experiência: o biológico, o psíquico, o social. Em outros termos, no centro de sua atenção, está o modo singularizado pelo qual o sujeito se apropria das diversas variantes e reproduz, à sua maneira, a existência.

No que diz respeito, então, às interações entre a motricidade corporal, a cultura material e as representações mentais, o postulado leva a abandonar todo e qualquer determinismo (presente em diversas versões do marxismo) ou pressuposto de homologia entre as estruturas (que encontramos no conceito de habitus de Bourdieu), para propor uma relação plural e não-necessária entre os elementos componentes da realidade. Evidentemente, é o fato de o sujeito ser o operador da articulação que permite uma tal maleabilidade. Daí Warnier instigar a antropologia a falar não apenas de identidade, mas também do "eu", concebido, ao exemplo de Foucault, como o sujeito das técnicas de si.

\section{Práticas e representações}

problema precedente repercute em outro paralelo, com implicações consideráveis tanto para o posicionamento dos estudos de cultura material como para um dos debates que divide a disciplina antropológica no último século: a articulação entre prática e representação.

Warnier identificou, corretamente, o predomínio das preocupações concernentes ao discurso no pensamento antropológico francês. De Durkheim a Lévi-Strauss, a corrente majoritária constituiu uma "antropologia das representações partilhadas", em detrimento da análise de outros elementos da ação social. Contrariamente, a contribuição de Mauss permitiria superar o impasse, integrando ao campo de consideração as práticas não-discursivas: o gestual ritual, a expressão corporal, etc. Poder-se-ia questionar legitimamente esse esforço de Warnier em 
opor Mauss à tradição: de fato, o texto sobre as técnicas corporais, que para Warnier é um dos pilares da teoria geral de Mauss sobre a religião, é considerado por muitos um hapax, sem conseqüências maiores sobre sua obra. Em todo caso, para nosso propósito, isso conta menos do que a apropriação particular do pensamento de Mauss por Warnier, a qual permite explicitar o problema da relação entre prática e representação.

Warnier enfatiza a distância entre esses dois níveis: a prática motriz e a prática discursiva. Haveria uma coincidência entre ambos, mas ela seria apenas parcial. $\bigcirc$ discurso - verbalizado ou não - não pode recobrir, e muito menos explicar, o conjunto de práticas exercidas pelo corpo e/ou baseadas na materialidade dos objetos. No limite, haveria mesmo uma diferença de natureza entre duas formas de pensamento: aquele que se gera na cabeça lque corresponde, então, à noção tradicional do pensamento cerebral), que tem característica homogeneizadora lo historiador reconhecerá, aqui, a condição sine qua non postulada pelos criadores da história das mentalidades) e, de outro lado, aquele cuja matriz é a própria dimensão corporal l"o homem é um animal que pensa com seus dedos", de acordo com a fórmula de Maurice Halbwachs, retomada por Mauss e herdada por Warnier). Este segundo nível de pensamento é eminentemente diferenciador: nele, com o concurso do corpo e da cultura material, o homem singulariza a sua existência social, constrói a si mesmo como sujeito. A questão que se apresenta, então, é a da articulação entre as condutas motrizes e os objetos, de um lado, e o imaginário, os símbolos, as representações, de outro. Uma vez mais, é Foucault que, na visão de Warnier, permite responder adequadamente a um problema apenas vislumbrado por Mauss: "o sujeito, pela prática, faz a síntese entre o objeto-corpo e o objeto-signo" (p. 82s.).

Não se trata, portanto, de uma simples inversão da equação. Warnier procura evitar o que chama de "aporia da causalidade" e as oposições artificiais entre mental e material, entre técnica e sociedade, entre sujeito e objeto. Sua terceira via, tendo Mauss como apoio, consiste em propor uma ação transitiva entre os diversos elementos da equação, evitando oposições apressadas, bem como determinismos incontornáveis. Para tanto, o foco é necessariamente deslocado para o que, segundo o autor, constitui a matriz ativa da ação social: não mais o ator inserido em sua categoria (grupo, classe, profissão), mas o sujeito, instância capaz de singularizar e dar consistência real ao ator social lque permaneceria como conceito fundamental, mas insuficiente, da sociologia).

\section{estudo da singularidade}

O predomínio da atenção sobre o discurso verificou-se, igualmente, no campo da cultura material. Nos primeiros estudos franceses sobre o "sistema de objetos", a partir da década de sessenta, percebe-se a influência marcante da abordagem semiológica: o objeto é, antes de mais nada, um signo. A cultura material é um sistema discursivo, e seu estudo, uma operação semiótica. Identificando Baudrillard como o mais representativo (e, ao mesmo tempo, mais caricatural) autor dessa corrente, Warnier reprova-lhe seja o postulado teórico que, transformando o objeto em unidade semântica, the subtrai toda materialidade -, seja o método, que conduziria a uma especulação exclusivamente abstrata, 
desprovida de enquete empírica e que não responderia aos protocolos científicos que permitem a verificação dos procedimentos de análise. As críticas a Baudrillard permitem explicitar alguns pontos de apoio das idéias de Warnier, que convém recapitular: a rejeição de uma abordagem generalizante, que mascara a particularidade das trajetórias individuais; a defesa da compreensão dos fenômenos sociais a partir de sua materialidade (corporal, objetual), e não apenas de sua natureza sígnica; a ênfase na observação de campo. Os estudos de cultura material inserem-se, assim, no quadro de uma etnologia da singularidade, que, opondo-se (ou, mais propriamente, somando-se) à antropologia das categorias, visa a entender as formas práticas de constituição do sujeito social. Não há, é preciso dizer, uma rejeição sumária da importância da norma, do discurso, dos enquadramentos sociais, mas uma decidida constatação de seus limites como instrumentos de explicação da realidade. A observação da relação corpo/universo físico ofereceria, então, uma ferramenta capaz de afinar a pesquisa, permitindo que o olhar do antropólogo penetre em uma dimensão marginalizada até então.

Um novo campo ou, simplesmente, um redimensionamento da escala de observação? É interessante notar que autores como Isabelle Garabuau-Moussaoui e Dominique Desjeux - que, não obstante, compartilham largamente do programa de Warnier - rejeitam o abandono de uma perspectiva mais ampla e propõem, no lugar de uma antropologia no singular, "uma antropologia social a uma escala micro-social" (2000, p. 20). Voltaremos a esse problema na conclusão; por enquanto, apenas notemos que os integrantes do grupo parecem hesitar em qualificar sua abordagem como uma ruptura radical perante a tradição antropológica, preferindo considerar a cultura material como uma chave de entrada inovadora para penetrar as antigas questões. De fato, nem nas considerações teóricas de Warnier nem nos diversos trabalhos empíricos do grupo existe uma renovação decisiva das temáticas de pesquisa. Assim, são recorrentes as problemáticas do consumo e da transmissão (ANDRYS, 2000; FRANÇOIS; DESJEUX, 2000), da organização da vida doméstica (PUTNAM; SWALES, 1999; TESTUT, 2000), ao lado de estudos monográficos sobre as trajetórias sociais de objetos particulares, como o livro (MARTIN, 2000), a fotografia (LEVÊQUE, 2000), o carro (GARABUAU-MOUSSAOUI, 2000).

objeto e a mercadoria a autentificação.

Resta, enfim, compreender um conceito-chave desenvolvido pelo grupo:

Warnier postula uma validade universal para a grade de análise proposta: das sociedades ditas tradicionais às sociedades industrializadas, o conjunto de ferramentas apresentado deve ser capaz de explicar a dinâmica da relação homem/matéria em toda a sua complexidade. No entanto, o autor reconhece as particularidades de cada uma das diversas formas de organização social e, por conseqüência, as diferenças de cada campo de estudo.

conceito de autentificação responde, de fato, às imposições da análise de um caso particular, aquele das sociedades modernas, em que o consumo de massa é o sistema de aprovisionamento por excelência e cujo funcionamento se desenrola segundo os parâmetros do mercado. Em tal situação, o objeto é, por 
assim dizer, despersonalizado, ou seja, reduzido à categoria de mercadoria, considerado apenas ou principalmente pelos atributos que permitem sua inclusão em um circuito econômico de massa. A sua equivalência em dinheiro cumpre justamente esse papel: doravante, ele é passivo de uma mensuração que o equaliza com todos os demais objetos do circuito, que permite seu deslocamento do produtor ao consumidor em um processo desprovido de "personalidade". Ora, nós sabemos que esse princípio (presente quer na teoria econômica clássica, quer nas diversas críticas da sociedade de consumol dá conta apenas muito imperfeitamente da realidade. A sociedade moderna se caracteriza, ao contrário, pela proliferação de bens e de circuitos cuja definição passa justamente pela distinção: os critérios históricos ou geográficos, a tradição, a produção de origem controlada, são mobilizados para conferir um estatuto distinto ao objeto lo queijo típico de uma região; as compotas feitas segundo as receitas dos monges da abadia tal; o mobiliário exótico, artesanal ou oriental, por exemplo). E eis, então, o "paradoxo da mercadoria autêntica": ela se distingue da massa de mercadorias pela incorporação de significados, num processo de autentificação, mas, ao mesmo tempo, integra o circuito econômico de mercado. $\bigcirc$ que, por definição, era inalienável (não se vende uma história!) transforma-se, na sociedade moderna, em mercadoria. Autenticidade e alienabilidade são incorporadas num mesmo objeto.

Vê-se bem que o conceito de mercadoria autêntica procura responder a um antigo problema da teoria social. De Marx a Baudrillard, passando pela escola de Frankfurt, a teoria da alienação foi uma das pedras de toque da análise, e da crítica, do sistema de objetos da sociedade moderna: a mercadização, implicando uma universalização do valor de troca através de sua expressão monetária, tenderia, nesta perspectiva, a esvaziar o objeto de toda a sua carga afetiva ou pessoal e a reduzi-lo a uma unidade mínima do sistema econômico. No entanto, segundo Warnier, uma série de constatações permitiria, ao menos, moderar um tal postulado. Em primeiro lugar, ao mesmo tempo em que contribui para a homogeneização dos produtos, o sistema industrial permite diversificar as mercadorias indefinidamente, aumentando as possibilidades de diferenciação e de subjetivação. Em segundo lugar, o processo de equivalência em valor-dinheiro não é de modo algum exclusivo e o acesso aos objetos não passa necessariamente pelo mercado. Por fim, a própria definição estática de mercadoria deveria ser revista: o estatuto de mercadoria não é uma natureza absoluta, inerente a uma certa categoria de objetos (em particular, os produtos da economia moderna), mas uma qualificação dinâmica, que marca uma fase na trajetória social do objeto. No entanto, mesmo após essas ressalvas, o próprio autor reconhece que o efeito da uniformização pelo mercado é tal que as práticas que visam a personalizar o objeto, a singularizá-lo, são insuficientes. De onde a importância do imaginário da mercadoria autêntica, esse conjunto de dispositivos mentais (manipulado, aliás, pela própria estratégia publicitária) que permite a existência, no interior do sistema, de elementos que, a princípio, the são contraditórios.

A noção de uma biografia da cultura material revela-se, assim, essencial para compreender como o objeto autêntico, por definição não-mercantilizável, apresenta-se sob a forma de uma mercadoria autêntica, podendo integrar as engrenagens do mercado. Reconhece-se, aqui, a que ponto o conceito de mercadoria autêntica é tributário e, ao mesmo tempo, um prolongamento das idéias de lgor Kopytoff que, em sua importante contribuição aos estudos de cultura material ( 1986), procurou alertar para o fato de que a mercadização não esgota 
o objeto e que as constantes integrações, mutações e reintegrações, com todas as implicações no nível das alterações de atributos, devem ser consideradas em uma análise da trajetória cultural do objeto.

Limites e perspectivas

A corrente aqui analisada é jovem e multiplica-se quer pela via dos trabalhos empíricos, das monografias aplicadas, quer pela via da reflexão teórica. Não cabe, nesta resenha, uma apreciação do seu lugar no quadro da antropologia contemporânea. Não sendo antropólogo, limitar-me-ei a duas ou três considerações finais, sob a óptica do historiador interessado no estudo da cultura material.

Um tal interesse cobre, de fato, dois campos que devem ser devidamente distintos. $\bigcirc$ primeiro é aquele da realidade histórica propriamente dita: o estudioso pode indagar-se sobre as formas de organização material da sociedade, sobre o processo de apropriação do universo material pelo grupo humano, sobre as relações sociais implicadas pela interação entre os homens e o meio, as estruturas e os objetos físicos, ou ainda sobre as representações coletivas que acompanham as práticas materiais. $\bigcirc$ segundo campo situa-se no nível historiográfico e remete diretamente à operação analítica que faz da cultura material uma fonte, um documento a ser mobilizado no estudo de um fenômeno social qualquer. As observações a seguir partem dessa distinção fundamental, mas se concentram no segundo aspecto.

Uma primeira característica, decorrente da própria natureza da abordagem antropológica, é a fraca atenção conferida aos aspectos diacrônicos das relações entre a sociedade e a cultura material. Apesar da ênfase na trajetória dos objetos e do cuidado em estabelecer uma sucessão de status da cultura material, as propostas de Warnier não estão fundadas teoricamente numa perspectiva histórica e não parecem prever os instrumentos metodológicos necessários à captação do fator temporal e de suas conseqüências. A visão que se delineia é, antes, estática ou, no melhor dos casos, composta por diferentes quadros consecutivos. Se a cultura material é mobilizada como elemento revelador das alterações dos comportamentos pessoais e grupais, por outro lado, é fracamente manipulada para se entender a dinâmica social como um todo, isto é, os fatores de ruptura e de continuidade. Cabe, imperativamente, ao historiador reintroduzir no quadro uma projeção temporal mais acurada.

Outra decorrência do método antropológico é que o entendimento da relação corpo/matéria é feito a partir de uma observação direta; dito de outro modo, da enquete etnográfica. Ora, para uma parte considerável das sociedades analisadas pelo historiador, um tal procedimento é impossível: o corpo, ao menos aquele provido de motricidade, é simplesmente uma dimensão perdida (deixando, no máximo, alguns traços que serão, é certo, proveitosamente integrados ao estudo). Retornamos, assim, ao problema do documento: o próprio método histórico leva a uma documentalização dos componentes do fenômeno estudado (textos; imagens; registro oral; cultura material...), como a via prioritária de acesso cognitivo ao próprio fenômeno. No caso em questão, exige a transformação da cultura material em documento, inclusive para o entendimento da sua relação com o corpo, sendo este pólo da equação presente apenas de modo residual ou indireto. Justamente, o corpo, que para o etnógrafo é uma dimensão observável, para o historiador 
será, ele mesmo, o resultado de uma inferência a partir dos documentos. Tais diferenças enfraquecem consideravelmente o potencial das propostas de Warnier, excessivamente dependentes da observação direta. Os requisitos de uma análise histórica seriam mais bem preenchidos, por exemplo, a partir dos modelos explicativos propostos pela arqueologia, que visam à reconstituição do gestual corporal pela análise dos traços físicos da cultura material, dos sinais de sua manipulação pelo homem, ainda que o próprio método arqueológico não dispense, por seu lado, a comparação etnográfica (ver, por exemplo, o interessante estudo de BEAUNE, 2000).

Problema da escala de observação já foi enunciado acima, bem como as divergências a seu respeito no interior do próprio grupo. Acrescentemos apenas que a questão é igualmente importante para o historiador, tendo sido abordada nos recentes debates na disciplina, e chamemos a atenção para a necessidade de se fazer uma distinção, ao se falar de micro-história, entre o que é um procedimento analítico (a adequação da escala na construção do objeto de observação) e o que é uma consideração sobre a realidade observada los níveis micro ou macro do fenômeno social). Quanto ao primeiro aspecto, a proposta de Warnier é bastante clara, como se viu. No entanto, as implicações de uma análise em microescala na confecção dos modelos explicativos não parecem encontrar um encaminhamento adequado, quer porque estes modelos tendem a perder o seu lugar, quer porque, o que é mais provável, os autores sintam uma dificuldade de articular o procedimento de pesquisa e a concepção acerca da dimensão do fenômeno estudado.

Por fim, uma reflexão teórica curta mas que nos parece importante: epistemologicamente, Warnier milita por uma abordagem da sociedade que valorize o indivíduo como elemento motor da ação social. Deste ponto de vista, as práticas de singularização seriam mais esclarecedoras do que as normas; do mesmo modo, o sujeito, mesmo que não seja entendido como um ser isolado, passaria a ser uma categoria analítica mais representativa do que aquela do ator social (vista, então, como uma espécie de abstração que diluiria a especificidade dos agentes). Num primeiro olhar, tratar-se-ia de uma antropologia mais histórica, se com isto pretendermos valorizar o caráter "événementiel" do discurso historiográfico. Todavia, tal ênfase não seria, justamente, uma contradição ante uma tendência mais conceitual, que marcou tão profundamente as últimas décadas da historiografia francesa? Ou, pelo contrário, a antropologia estaria apenas acompanhando, e subsidiando, a história em seu abandono da ambição generalizante, da explicação sintética, em benefício de uma abordagem singularizada, de um saber local, que parecem constituir o mais recente farol dos Annales, a ponto de se ter podido falar de uma "história em migalhas"? Neste caso, não estariam ambas as disciplinas caminhando para uma nova forma de determinismo, do indivíduo e do individual, depois de terem experimentado a tirania da classe e o imperialismo do signo e das mentalidades?

\section{REFERÊNCIAS}

ANDRYS, Christine. Les cadeaux: règles et itinéraires des pratiques de don. In: GARABUAUMOUSSAOUI, Isabelle; DESJEUX, Dominique (Ed.). Objet banal, objet social. Les objets quotidiens comme révélateurs des relations sociales. Paris: L'Harmattan, 2000. 
BAUDRILLARD, Jean. Le système des objets. Paris: Gallimard, 1968.

BEAUNE, Sophie A. de. Pour une archéologie du geste. Paris: CNRS Editions, 2000.

FRANÇOIS, Tine Vinje; DESJEUX, Dominique. L'alchimie de la transmission sociale des objets. Comment réchauffer, entretenir ou refroidir les objets affectifs en fonction des stratégies de transfert entre générations. In: GARABUAU-MOUSSAOUI, Isabelle; DESJEUX, Dominique (Ed.). Objet banal, objet social. Les objets quotidiens comme révélateurs des relations sociales. Paris: L'Harmattan, 2000 .

GARABUAU-MOUSSAOUI, Isabelle. "Roulez jeunesse". La voiture comme analyseur des relations parents/jeunes. In: GARABUAU-MOUSSAOUI, Isabelle; DESJEUX, Dominique (Ed.). Objet banal, objet social. Les objets quotidiens comme révélateurs des relations sociales. Paris: L'Harmattan, 2000.

GARABUAU-MOUSSAOUI, Isabelle; DESJEUX, Dominique.Introduction. In: GARABUAU-MOUSSAOUI, Isabelle; DESJEUX, Dominique (Ed.). Objet banal, objet social. Les objets quotidiens comme révélateurs des relations sociales. Paris: L'Harmattan, 2000.

GRAS, Michel.Donner un sens à l'objet.Archéologie, technologie culturelle et anthropologie.Annales, v. 55, n. 3, p. 601-614, 2000.

HALTIM, Nadine. La vie des objets. Paris: L'Harmattan, 1996.

JULIEN, Marie-Pierre. Des “techniques du corps"à la synthèse corporelle:mises en objets.In:JULIEN, Marie-Pierre;WARNIER, Jean-Pierre (Ed.).Approches de la culture matérielle - corps à corps avec l'objet. Paris: L'Harmattan, 1999. p. 15-27.

JULIEN, Marie-Pierre; WARNIER, Jean-Pierre (Ed.). Approches de la culture matérielle - corps à corps avec l'objet. Paris: L'Harmattan, 1999.

KOPYTOFF, I.The cultural biography of things: commoditization as process. In:APPADURAI,Arjun (Ed.).The social life of things. Commodities in cultural perspective. Cambridge: Cambridge University Press, 1986.

LEVÊQUE, Claire-Marie. Les photographies, des vies mises en images. In: GARABUAU-MOUSSAOUI, Isabelle; DESJEUX, Dominique (Ed.). Objet banal, objet social. Les objets quotidiens comme révélateurs des relations sociales. Paris: L'Harmattan, 2000.

MARTIN, Olivier.Le livre, les livres, dans la maison. Pour une sociologie de l'objet livre. In: GARABUAUMOUSSAOUI, Isabelle; DESJEUX, Dominique (Ed.). Objet banal, objet social. Les objets quotidiens comme révélateurs des relations sociales. Paris: L'Harmattan, 2000.

MAUSS, Marcel. Les techniques du corps.Journal de Psychologie, v. 32, n. 3/4, 1936. (reeditado em: MAUSS, Marcel. Sociologie et anthropologie. Paris: PUF, 1985. p. 365-86.)

MOLES,Abraham A. Théorie des objets. Paris: Presses Universitaires de France, 1972. 
PARLEBAS, Pierre. Les tactiques du corps. In: JULIEN, Marie-Pierre; WARNIER, Jean-Pierre. (Ed.). Approches de la culture matérielle - corps à corps avec l'objet. Paris: L'Harmattan, 1999b. p. 29-43.

PARLEBAS, Pierre (Ed.). Le corps et le langage: parcours accidentés. Paris: L'Harmattan. 1999a.

PESEZ, Jean-Marie. Histoire de la culture matérielle. In: LE GOFF,J.; CHARTIER, R.; REVEL, J. (Ed.). La nouvelle histoire. Paris: Retz, 1978.

REVEL,Jacques (Ed.).Jeux d'échelles. La micro-analyse à l'expérience. Paris: EHESS/Gallimard/Seuil, 1996.

ROCHE, Daniel. Histoire des choses banales. Naissance de la consommation, XVII ${ }^{\mathrm{e}}-\mathrm{XIX}^{\mathrm{e}}$ siècle. Paris: Fayard, 1997.

TESTUT, Nina. Du mot d'amour à la liste de courses: place et fonctions de la communication écrite dans le couple. In: GARABUAU-MOUSSAOUI, Isabelle; DESJEUX, Dominique (Ed.). Objet banal, objet social. Les objets quotidiens comme révélateurs des relations sociales. Paris: L'Harmattan, 2000.

WARNIER,Jean-Pierre. Construire la culture matérielle. L'homme qui pensait avec ses doigts. Paris: Presses Universitaires de France, 1999a.

WARNIER, Jean-Pierre. Culture matérielle et subjectivation. In: PARLEBAS, Pierre (Ed.). Le corps et le langage: parcours accidentés. Paris: L'Harmattan. 1999c.

WARNIER, Jean-Pierre (Ed.). Le paradoxe de la marchandise authentique. Imaginaire et consommation de masse. Paris: L'Harmattan, $1994 \mathrm{a}$.

WARNIER,Jean-Pierre.Six objets en quête d'authenticité.In:WARNIER,Jean-Pierre (Ed.). Le paradoxe de la marchandise aubentique. Imaginaire et consommation de masse. Paris: L'Harmattan, 1994b. p. 11-31.

WARNIER, Jean-Pierre. Le sujet comme "roue d'engrenage". In:JULIEN, Marie-Pierre;WARNIER, JeanPierre. (Ed.). Approches de la culture matérielle - corps à corps avec l'objet. Paris: L'Harmattan, $1999 \mathrm{~b}$.

WARNIER,Jean-Pierre; ROSSELIN, Céline (Ed.).Authentifier la marchandise. Anthropologie critique de la quête d'authenticité. Paris: L'Harmattan, 1996.

Artigo reapresentado em 2/2003. Aprovado em 9/2003. 
Estudos de Cultura Material: uma vertente francesa

Marcelo Rede

Surgida na França, no âmbito dos estudos antropológicos e sociológicos, uma tendência recente de análise da cultura material se firma como uma alternativa à tradição anglo-americana dos material culture studies. Este artigo procura definir suas características predominantes, avaliando suas possibilidades e seus limites para o trabalho do historiador.

PALAVRAS-CHAVE: Cultura Material. Sociologia. França.

Anais do Museu Paulista. São Paulo. N. Sér. v. 8/9. p.281-291 (2000-2001). Editado em 2003.

Material Culture Studies: a French stream

Marcelo Rede

Arisen in France, in the scope of the anthropological and sociological studies, a recent analysis tendency of the material culture settles as an alternative to the Anglo-American tradition of the 'material culture studies'. This article wants to define its predominant characteristics, evaluating its possibilities and its limits for the historian's work.

KEYWORDS: Material Culture. Sociology. France.

Anais do Museu Paulista. São Paulo. N. Sér. v. 8/9. p.281-291 (2000-2001). Editado em 2003.

Gênero e Cultura Material: uma introdução bibliográfica

Vânia Carneiro de Carvalho

Este artigo discute as contribuições de historiadores, curadores, arquitetos, arqueólogos, antropólogos, entre outros, na produção de um objeto de conhecimento recente- a história do gênero na perspectiva da cultura material. Á confluência das duas áreas vem enriquecendo a compreensão da natureza culturalmente sexuada das práticas sociais. Nesse casamento, no entanto, somaram-se problemas teórico-metodológicos que merecem explicitação. Apesar da abrangência do campo, especial atenção foi dada para a produção bibliográfica que trata da formação do espaço doméstico ocidental burguês. Tal recorte justifica-se por entendermos que a casa é o local privilegiado de construção do gênero através de dispositivos materiais.

PALAVRAS-CHAVE: História da Mulher. História da Família. Espaço Doméstico. Cultura Material. História do Gênero.

Anais do Museu Paulista. São Paulo. N. Sér. v. 8/9. p.293-324 (2000-2001). Editado em 2003.

Gender and Material Culture: a bibliographic introduction

Vânia Carneiro de Carvalho

This article discusses the contributions of historians, curators, architects, archaeologists, and anthropologists, among others, in the production of an object of recent knowledge - the History of Gender in the perspective of material culture. The confluence of the two areas has been enriching the comprehension of the culturally sexual nature of the social practices. In this marriage, however, theoretical-methodological matters, which deserve a word about, have been added. Such attention is due to our understanding that home is the best place for the construction of Gender through material artefacts.

KEYWORDS:Woman's History. Family's History. Domestic Space. Material Culture. Gender's History. Anais do Museu Paulista. São Paulo. N. Sér. v. 8/9. p.293-324 (2000-2001). Editado em 2003. 